\title{
MAPEAMENTO DO USO E OCUPAÇÃO DA TERRA NO MUNICÍPIO DE JAGUARI - RS
}

\author{
Eloisa Penna da Rosa ${ }^{(a)}$, Romario Trentin $^{(\mathrm{b})}$, Daniélli Flores Dias ${ }^{(\mathrm{c})}$, Vinicius Silveira dos \\ Santos ${ }^{(\mathrm{d})}$
}

(a) Departamento de Geociências/Universidade Federal de Santa Maria, E-mail: eloisapenna@ hotmail.com

(b) Departamento de Geociências/Universidade Federal de Santa Maria, E-mail: romario.trentin@ gmail.com

(c) Departamento de Geociências/Universidade Federal de Santa Maria, E-mail: daniellidias08@ gmail.com

(d) Departamento de Geociências/Universidade Federal de Santa Maria, E-mail: viniciusgeografia93@gmail.com

Eixo: Uso e ocupação das terras e legislação ambiental

\begin{abstract}
Resumo
Conhecer os modelos atuais de uso e ocupação da terra faz-se necessário para o ordenamento do território. Diante disso, buscou-se analisar a dinâmica do uso e ocupação da terra no município de Jaguari, que localiza-se na região centro-oeste do Estado do Rio Grande do Sul, entre as coordenadas

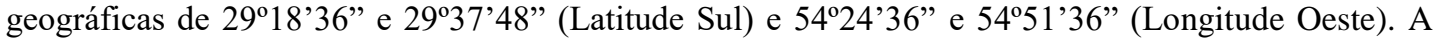
elaboração do mapa de uso e ocupação da terra foi feita através da utilização de imagens do satélite LANDSAT 8 OLI. A classificação das imagens ocorreu pela utilização do softwares ENVI 5.1 e ArcGIS ${ }^{\circledR} 10.1$ onde foram identificadas as seguintes classes: água, área urbana, campos, florestas e lavouras. Através do levantamento das classes do uso e ocupação da terra do município de Jaguari foi possível discriminar o potencial e as limitações de uso dos recursos naturais e propor o uso compatível da terra visando sua sustentabilidade.
\end{abstract}

Palavras chave: Ordenamento; Território; Sensoriamento remoto; Geoprocessamento.

\section{Introdução}

Conhecer os modelos atuais de uso da terra e as mudanças ocorridas nos últimos anos, faz-se necessário para a gestão sustentável dos recursos naturais. Logo, as áreas do conhecimento envolvendo as geotecnologias teve um crescimento técnico-cientifico considerável, podendo ser utilizada pelos órgãos governamentais na identificação das potencialidades e fragilidades de cada região.

Nesse sentido, o mapeamento de uso e ocupação da terra torna-se importante ferramenta na interpretação da distribuição espacial dos tipos de ações causadas pelo homem através da análise de imagens de satélites, demonstrando-se de grande importância para os estudos de natureza geoambiental. Diante dessa perspectiva, realizou-se o mapeamento e a caracterização do espaço geográfico do município de Jaguari, com o objetivo de compreender a dinâmica do uso e ocupação da terra no ano de 2016.

A área de estudo, localiza-se na região centro-oeste do Estado do Rio Grande do Sul, entre as coordenadas

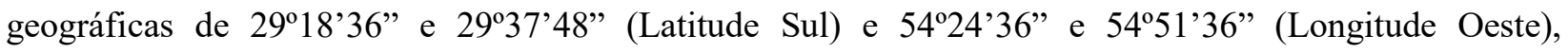




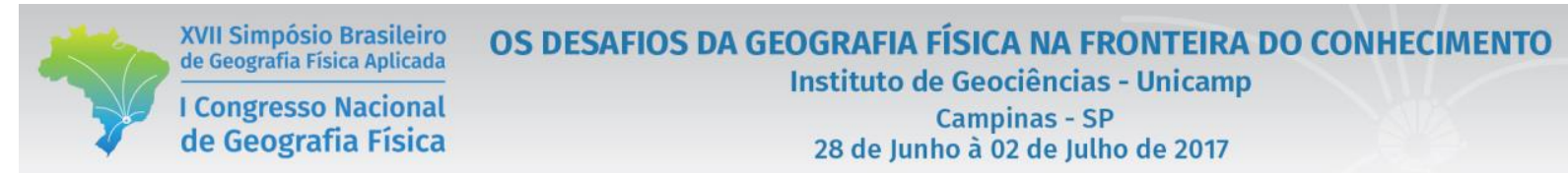

limitando-se com os seguintes municípios: São Francisco de Assis, São Vicente do Sul, Mata, Toropi, Jari, Santiago e Nova Esperança do Sul. Possui uma população de 11.473 habitantes e uma área territorial de 673,401 km², segundo os dados do Instituto Barsileiro de Geografia e Estatística (IBGE, 2010). A Figura 1 apresenta a localização do município de Jaguari.

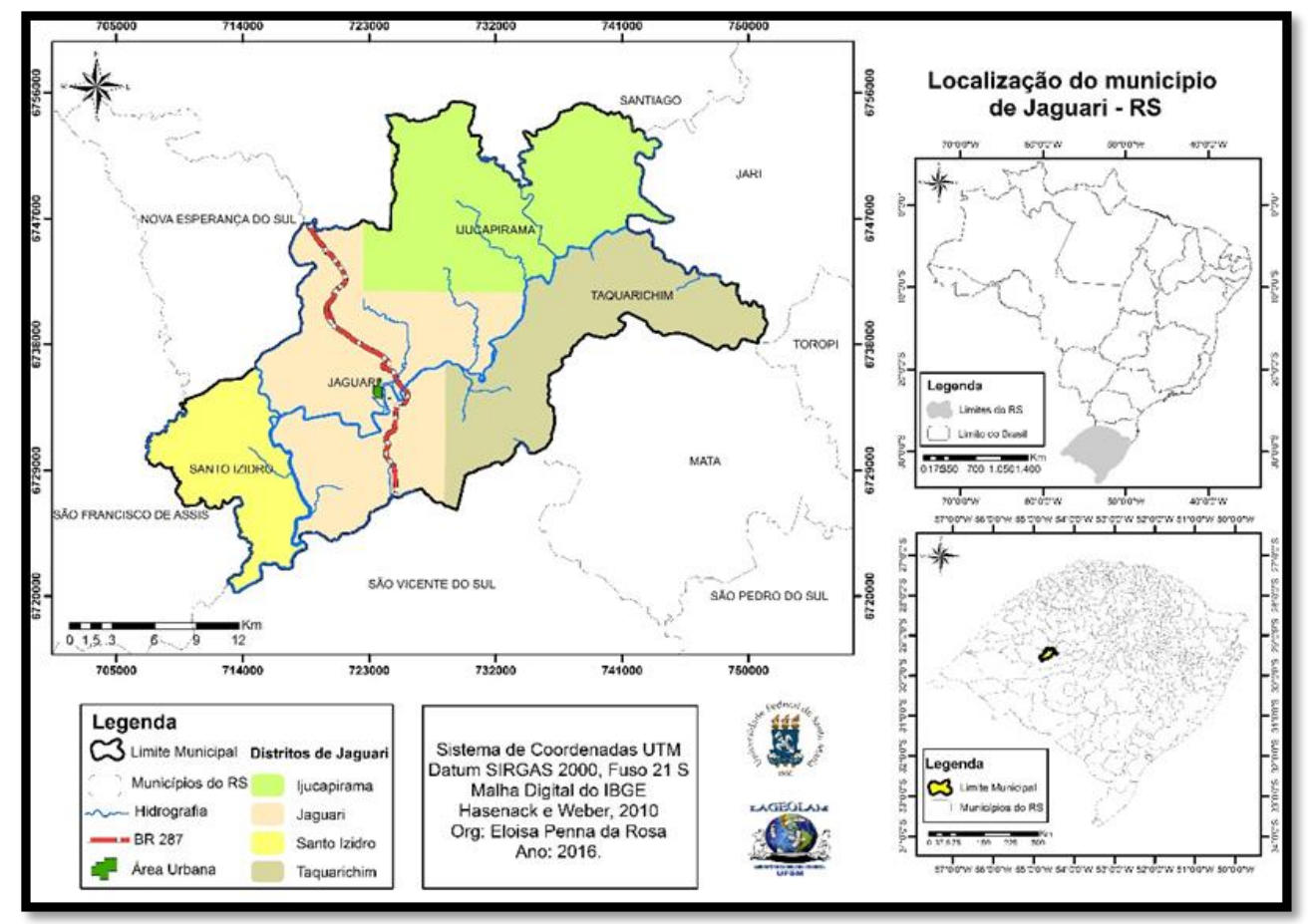

Figura 1 Localização do município de Jaguari - RS.

\section{Metodologia de Trabalho}

Primeiramente foi feito um levantamento bibliográfico sobre o tema a ser estudado. Logo em seguida, o trabalho de campo no município de Jaguari foi essencial para conhecer a formas de uso e ocupação da terra da área em estudo, e assim definir as classes a serem trabalhadas.

As imagens para a elaboração do mapa de uso e ocupação da terra do município foram obtidas através do portal online (http://earthexplorer.usgs.gov/) do Serviço Geológico dos Estados Unidos (USGS). A imagem utilizada foi do satélite LANDSAT 8 com resolução espacial de 30 metros, sensor OLI, utilizandose as bandas 1,2,3,4,5,6,7 e 8, datadas de 02 de setembro de 2015 .

Para a classificação da imagem utilizou-se a ferramenta Maxver (máxima verossimilhança) que é um algoritmo de classificação supervisionada, que usa parâmetros estatísticos na classificação de pixels de valores semelhantes, visando áreas semelhantes ou de mesmo valor numérico. Esse processo foi feito 


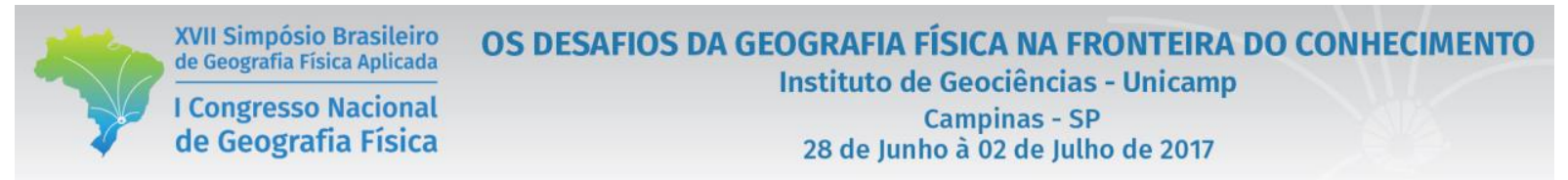

junto ao software ENVI 4.8 e posteriormente a imagem classificada foi importada para o ArcGIS® 10.1 onde ocorreu a finalização do mapa de uso e ocupação.

E assim, a partir das imagens de satélite juntamente com as técnicas de geoprocessamento e trabalho de campo foi possível delimitar as seguintes classes de uso e ocupação: água, área urbana, campos, florestas e lavouras.

\section{Resultados e Discussões}

Foram definidas cinco classes distintas de uso e ocupação da terra no município de Jaguari: água, área urbana, campos, florestas e lavouras.

Na Figura 2 é apresentado o mapa de uso e ocupação da terra de Jaguari e na Tabela 1 a área e porcentagem dos diferentes tipos de classes de uso.

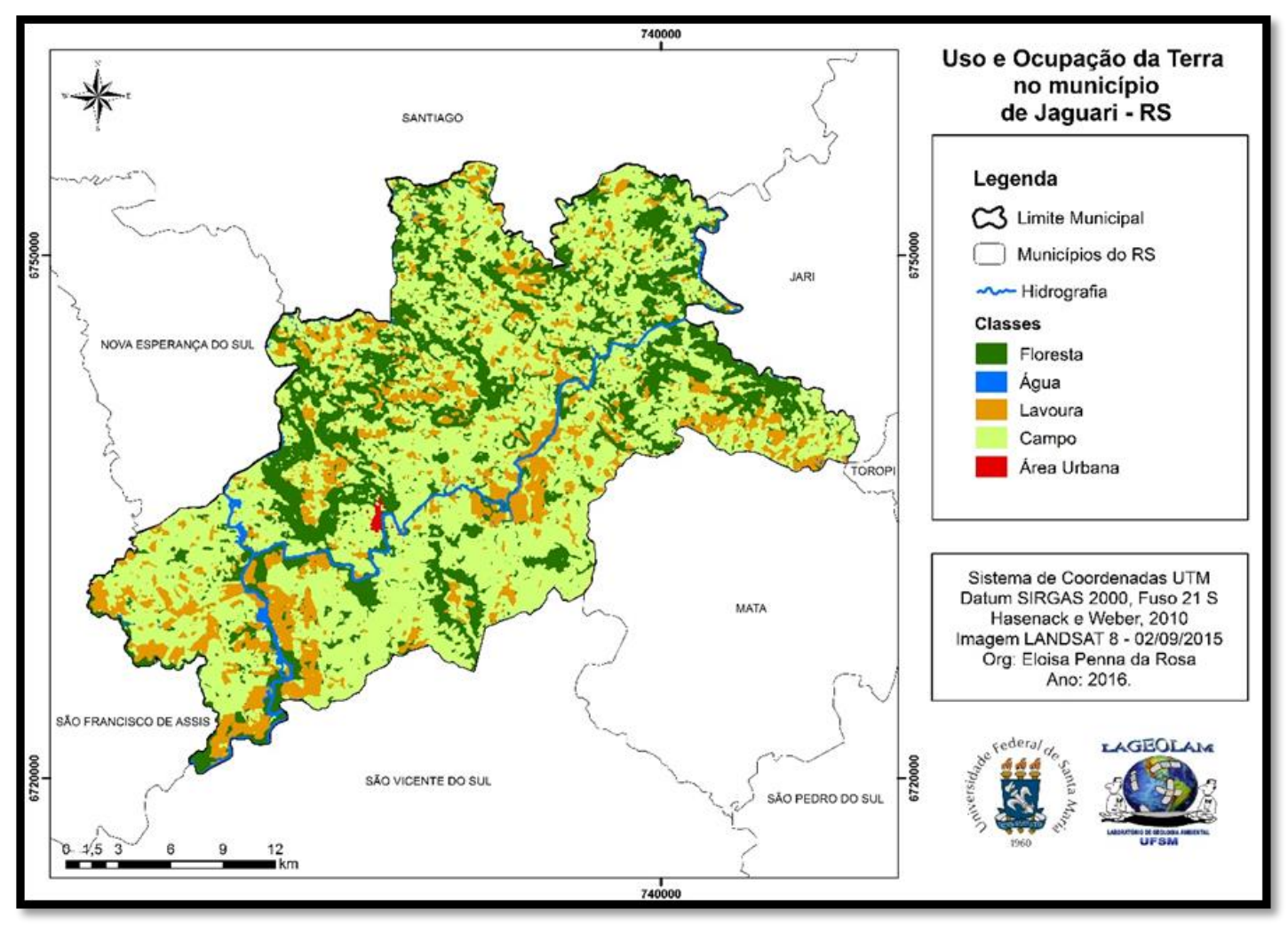

Figura 2 Uso e Ocupação da Terra no município de Jaguari - RS

Figura 3 Área e porcentagem das classes de uso e ocupação da terra no Município de Jaguari - RS

Tipo de Uso

Área $\left(\mathrm{km}^{2}\right)$

Porcentagem (\%) 


\begin{tabular}{ccc}
$\begin{array}{c}\text { XVII Simpósio Brasileiro } \\
\text { de Geografia Fisica Aplicada }\end{array}$ & $\begin{array}{c}\text { OS DESAFIOS DA GEOGRAFIA FíSICA NA FRONTEIRA DO CONHECIMENTO } \\
\text { Instituto de Geociências - Unicamp } \\
\text { I Congresso Nacional } \\
\text { de Geografia Física }\end{array}$ & $\begin{array}{c}\text { Campinas - SP } \\
\text { de Junho à 02 de Julho de 2017 }\end{array}$ \\
\hline Campos & $351,39 \mathrm{~km}$ & 52,18 \\
Florestas & $180,76 \mathrm{~km}$ & 26,84 \\
Lavouras & $123,86 \mathrm{~km}$ & 18,39 \\
Água & $16,28 \mathrm{~km}$ & 2,41 \\
Área Urbana & $1,12 \mathrm{~km}$ & 0,16 \\
\hline
\end{tabular}

Os campos é a classe que mais predomina no município de Jaguari, com 52,18\% do total da área de estudo. São formados por uma vegetação de gramíneas e pequenos arbustos destinadas a pecuária extensiva, caracterizada pela utilização de métodos tradicionais, onde o gado é criado solto.

As florestas são a segunda maior classe encontradas no município de Jaguari, abrangendo 26,84\% da área total. Essa unidade compreende a área de vegetação de médio a grande porte, bem como as áreas destinadas a silvicultura, principalmente o plantio de eucalipto bastante

presente no município. Encontram-se junto as drenagens e em regiões de transição do relevo, ou seja, entre o Planalto Meridional e a Depressão Periférica.

No caso da classe de uso de lavouras, essa abrange as áreas de cultivo das principais culturas: fumo, soja, arroz, milho, cana-de-açúcar, batata-doce, feijão, mandioca e as pastagens. As lavouras de arroz se encontram próximas as drenagens, enquanto que o cultivo do fumo ocorrem nas áreas mais acidentadas do relevo. Essa classe representa cerca de 18,39\% da área total do município.

Já a classe de uso que corresponde a água representa 2,41\% da área em estudo e caracteriza- se pelos rios (Jaguari, Jagiarizinho e seus afluentes) e açudes. A água além de ser utilizada na produção agrícola, serve para saciar a sede dos rebanhos, assim como para o abastecimento da população do município.

Por fim, a classe do urbano ocupa a menor área de uso o que representa apenas 0,16\% da área total. Essa área localiza-se próxima ao rio Jaguari e abriga $56,92 \%$ da população total do município. O sistema urbano é constituído pelos bairros Centro, Consolata,

Mauá, Rivera, Santa Rosa, Sagrado Coração de Jesus, Promorar, Nossa Senhora de Lourdes e Nossa Senhora Aparecida.

\section{Considerações Finais}

O emprego das técnicas de Geoprocessamento e Sensoriamento Remoto mostrou-se de grande importância no mapeamento do uso e ocupação da terra no município de Jaguari - RS. O levantamento de dados a partir das imagens de satélites, juntamente com os trabalhos de campos e estudos existentes, possibilitou a geração de informações que indicam a localização e a 
ocorrência de alterações ocorridas na área de estudo e eficazes na identificação da exploração dos recursos naturais, sendo fundamentais para o conhecimento das áreas degradadas e no ordenamento do território.

Por fim, no mapeamento do uso e ocupação da terra de Jaguari foi possível identificar o predomínio das áreas de campos (52,17\%), seguidas pelas áreas de florestas $(26,84 \%)$ e de lavouras $(18,39 \%)$, com destaque para a produção de fumo, soja, arroz, milho, cana-de-açúcar, e a criação de bovinos de corte, suínos e outros.

\section{Bibliografia}

ENVIRONMENTAL SYSTEMS RESEARCH INSTITUTE. ArcGIS ${ }^{\circledR} 10.1$ License Manager and Installation. Disponível em: <http://desktop.arcgis.com/en/desktop/latest/get-started/license-manager-guide/license-managerinstallation-and-startup.htm/>. Acesso em: 10 mar. 2016.

INSTITUTO BRASILEIRO DE GEOGRAFIA E ESTATÍSTICA - IBGE. Disponível em: 〈www.ibge.gov.br〉. Acesso em: 04 jun. 2016.

INSTITUTO BRASILEIRO DE GEOGRAFIA E ESTATÍSTICA. Dados do Município de Jaguari. Disponível em: <http://cidades.ibge.gov.br/xtras/perfil.php?codmun=431110>. Acesso em: 10 mar. 2016.

UNITED STATES GEOLOGICAL SURVEY. Imagens Landsat 5 e Landsat 8. Disponível em: < https://earthexplorer.usgs.gov/>. Acesso em: 29 out. 2016. 